\title{
THE MENISCOFEMORAL LIGAMENTS OF THE KNEE
}

\author{
A. R. POYNTON, S. M. JAVADPOUR, P. J. FINEGAN, M. O'BRIEN
}

From Trinity College, University of Dublin, Ireland

The meniscofemoral ligaments (MFL) of the knee have both functional and clinical importance, but have been poorly described. We examined 42 human cadaver knees: there was at least one MFL in every joint and both ligaments were present in 27. The anterior MFL was present in the knees in all 18 males and in 17 of the 24 females. The posterior MFL was present in $\mathbf{1 6}$ males and 22 females. Measurement of the ligaments showed that they were of significant size. The mean midpoint width for the anterior MFL was $5.09 \pm 1.41 \mathrm{~mm}$ in males and $2.99 \pm 1.29 \mathrm{~mm}$ in females. The mean width of the posterior MFL was $5.48 \pm 2.13 \mathbf{m m}$ in males and $3.79 \pm$ $2.56 \mathrm{~mm}$ in females. The average length of the anterior MFL was $27.09 \pm 2.15 \mathrm{~mm}$ in males and $24.38 \pm 3.39 \mathrm{~mm}$ in females, and the posterior MFL was $31.13 \pm 2.54 \mathrm{~mm}$ and $27.59 \pm 3.74 \mathrm{~mm}$, respectively. There were anatomical variations in $16(38 \%)$ knees (62.5\% female, $37.5 \%$ male), more commonly in the posterior ligament.

We conclude that the meniscofemoral ligaments are anatomically and probably functionally important structures in the human knee.

J Bone Joint Surg [Br] 1997;79-B:327-30.

Received 7 April 1996; Accepted after revision 30 September 1996

Although the anterior and posterior meniscofemoral ligaments (MFL) of the knee, also known as the ligaments of Humphry and Wrisberg, are well recognised, their descriptions have shown great variation, especially in relation to occurrence, size and anatomy. While the protective influence of the MFL on the posterior horn of the lateral meniscus has been addressed, ${ }^{1-5}$ the complex functional anatomy of this region is not fully understood. Clarification of the anatomy of these ligaments may have importance in clinical examination $^{6-8}$ and $\mathrm{MRI}^{9-12}$ of the knee. We aimed

\footnotetext{
A. R. Poynton, FRCS I, Registrar in Orthopaedic Surgery

St Vincent's Hospital, Elm Park, Dublin 4, Ireland.

S. M. Javadpour, FRCS I, Registrar in General Surgery

Ardkeen Regional Hospital, Co. Waterford, Ireland.

P. J. Finegan, MB, Lecturer in Anatomy

M. O'Brien, FRCP I, Professor of Anatomy

Trinity College, Dublin 2, Ireland.

Correspondence should be sent to Mr A. R. Poynton at 38 Balally Drive, Dundrum, Dublin 14, Ireland.

C 1997 British Editorial Society of Bone and Joint Surgery 0301-620X/97/26893\$2.00
}

to delineate the anatomy, size and occurrence of the meniscofemoral ligaments.

\section{MATERIALS AND METHODS}

After removal of the skin and subcutaneous tissue from 42 human cadaver knees (18 male and 24 female) the ligamentum patella was divided at its tibial insertion. An anterior approach was used to expose the anterior MFL (AMFL). A longitudinal incision was made in the capsule on each side of the joint and the two connected transversely at the tibial margin. The capsular flap including the patella and its ligamentous attachments were reflected superiorly. A constant fat pad at the femoral insertion of the anterior cruciate ligament (ACL) was removed. The knee was then flexed to expose the ACL which was divided. This revealed the posterior cruciate ligament (PCL). If an AMFL was present, it was on the anterior surface of the PCL. In order to allow clear and complete visualisation of the posterior MFL (PMFL) a posterior approach was required. The cadaver was turned to the prone position. After removal of skin the popliteal vessels and nerve were dissected and retracted medially to expose the posterior joint capsule. A longitudinal incision was made in the capsule over each femoral condyle. These were joined in the form of an inverted U. The capsular flap was reflected inferiorly and carefully separated from underlying structures before being removed completely from its distal attachments. If a PMFL was present it could be seen on the posterior surface of the PCL. The posterior horn of the lateral meniscus and attached MFL, when present, were easily seen. The occurrence, anatomy, length, and midpoint width of the MFLs were recorded, together with comments about variations.

\section{RESULTS}

All 42 knees had a meniscofemoral ligament. There were anterior and posterior divisions in 27 (64\%). Table I shows the incidence of each ligament in males and females, and the dimensions of the MFL are shown in Table II. An AMFL was present in all males, but only in $17(71 \%)$ females. A PMFL

Table I. Incidence of the meniscofemoral ligaments related to gender

\begin{tabular}{lllll}
\hline & Number & AMFL & PMFL & Both coexisting \\
\hline Male & 18 & 18 & 16 & 16 \\
Female & 24 & 17 & 22 & 11 \\
\hline
\end{tabular}


Table II. Dimensions ( $\mathrm{mm} \pm \mathrm{SD}$ ) of the meniscofemoral ligaments

\begin{tabular}{lrrrr}
\hline & AMFL (m) & AMFL (f) & PMFL (m) & PMFL (f) \\
\hline Mean length & $27.1 \pm 3.4$ & $24.4 \pm 3.4$ & $31.1 \pm 2.5$ & $27.6 \pm 3.7$ \\
Mean width of midpoint & $5.1 \pm 1.4$ & $2.9 \pm 1.3$ & $5.5 \pm 2.1$ & $4.7 \pm 2.4$ \\
\hline
\end{tabular}

was found in $16(89 \%)$ males and $22(92 \%)$ females. In both sexes the PMFL tended to be larger than the AMFL.

Anatomical description. The most common anatomical arrangement of the MFL is shown in Figure 1. The ligament arises from the posterior horn of the lateral meniscus, posterior and lateral to its tibial attachment. Usually the origin was a single thick band that divided immediately into two branches. That which passed posterior to the PCL is the PMFL, also known as the ligament of Wrisberg. It continued obliquely upwards and medially to insert into the lateral aspect of the medial femoral condyle slightly posterior and inferior to the insertion of the PCL, although in many knees the two ligaments were inseparably blended at this level. The other part passed anterior to the PCL and is the AMFL, or ligament of Humphry. It was noted to run proximally and medially between the cruciate ligaments. It appeared more intimately associated with the PCL and was often irreparably blended with it. Its insertion was just anterior and inferior to the PCL insertion. Figures 2 and 3 show two dissected specimens to illustrate the anatomy.

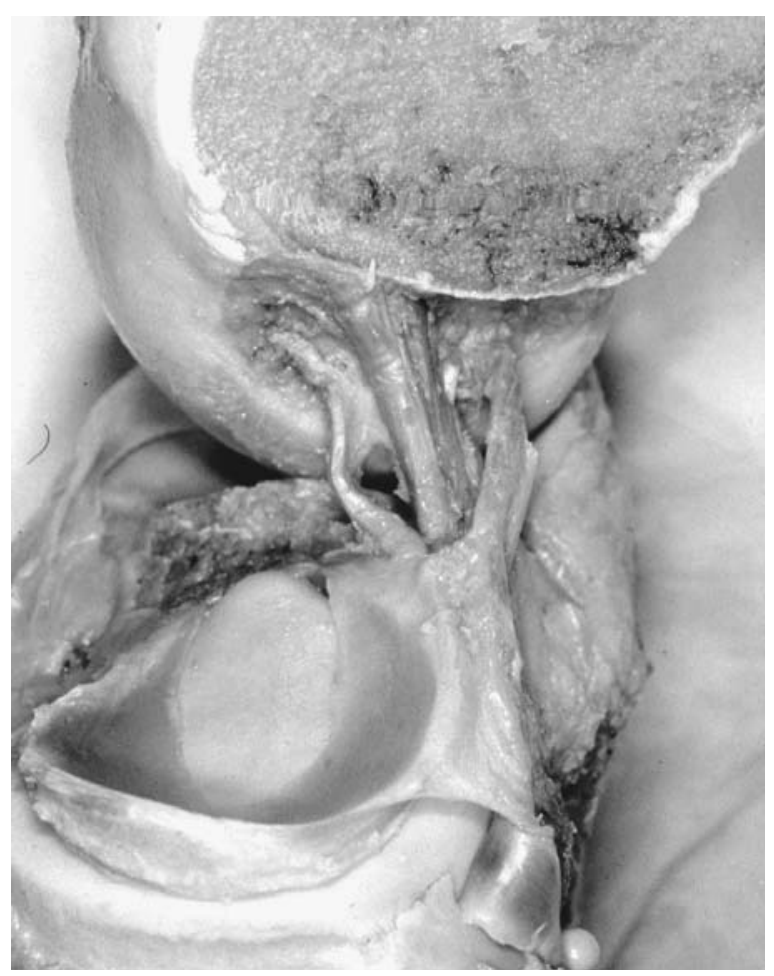

Fig. 2

A cadaver specimen, with the lateral femoral condyle and anterior cruciate ligament removed, showing anterior and posterior meniscofemoral ligaments of equal size.

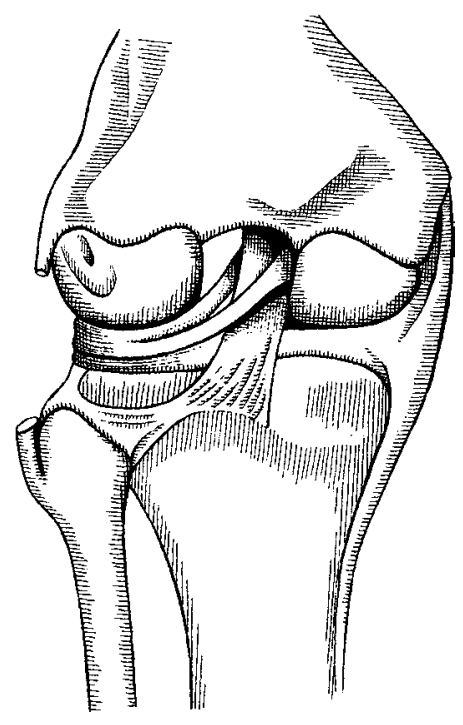

Fig. 1

Diagram of a posterior view of the knee to show the normal anatomy of the meniscofemoral ligaments.

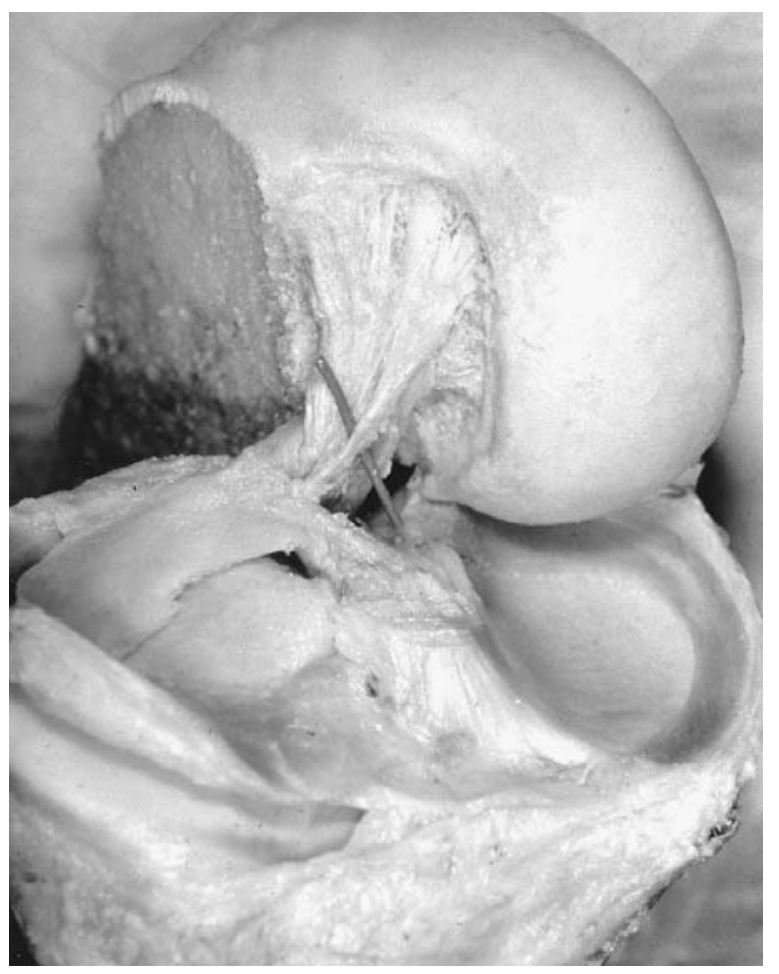

Fig. 3

A cadaver specimen demonstrating ligaments of different size. 
Variants. Variations from the most common pattern occurred in 16 (31\%) knees, involving the PMFL in 13 (31\%) cases ( 7 female, 6 male). There were only three variations (7\%) of the AMFL, all in females.

$P M F L$ variants. In ten cases an accessory band was seen to arise from the tibia just posterolateral to the medial articular surface and run superoanteriorly to join the PMFL near its femoral attachment. In one case this band was thicker than the PCL while in one other knee the PMFL consisted of two bands. One band arose below the other, and received a tibial accessory band. Two thin flat bands were seen in one knee. There was no accessory tibial band. An hourglass-shaped PMFL in one case had a wide origin and insertion and a narrow waist. In this knee the popliteus muscle was inserted into the PMFL for some distance medially on its inferior margin. In one knee the PMFL was seen to divide and then reunite. The posterior horn of the lateral meniscus was not attached to the tibia.

AMFL variants. The AMFL in one knee consisted of three distinct bands arising and inserting separately over wide areas. In one knee the AMFL was small and arose from the posterior horn of the lateral meniscus at its tibial attachment. The lateral meniscus in one knee had a small posterior tibial insertion with most of the posterior horn sweeping upwards to be continued as a large AMFL. On the anterior aspect of the PCL the superolateral half of the AMFL was completely separate, but the inferomedial half was inseparably blended with the underlying cruciate ligament.

\section{DISCUSSION}

The MFLs have been described by a number of anatomists, but the reports ${ }^{4,5,13-20}$ conflict in relation to their incidence and anatomy. The reported incidence ranges from $70 \%$ to 100\%: anterior $26 \%$ to $50 \%$, posterior $35 \%$ to $76 \%$, with both present in only $6 \%$ to $17 \%$ of knees. Many variations have been described and most classifications are confus- ing. ${ }^{15,16}$ We found an MFL in all 42 knees, with both present in 27 of 42 knees, a higher incidence than previously reported. The ligaments are of variable size, with the PMFL larger than the AMFL in both sexes. We found variations in anatomy in 16 of 42 knees; the most common was an accessory tibial band associated with the PMFL in ten.

Lahlaidi and Vaclavek, in a study of human embryo knees, ${ }^{21}$ put forward an embryological explanation for the variation in incidence and size of the MFL, suggesting that the position of the posterior horn of the lateral meniscus in relation to the PCL during organogenesis could explain them. The MFL seemed to develop as a single structure from the posterior horn of the lateral meniscus; the position of the PCL then appeared to determine whether this single structure split into two parts, remained single or developed any other variation in both form and size.

There are several studies on diagnostic imaging of these ligaments; MRI is commonly used, particularly in North America. Watanabe stressed that on MRI the MFL could be mistaken for intra-articular loose bodies, ${ }^{9,10}$ and Vahey showed that the appearance of the MFL could be mistaken for a pseudotear of the lateral meniscus. ${ }^{11}$ This is because of the parallel course of the two parts of the MFL near their insertion into the posterior horn of the lateral meniscus; Figure 4a shows an MR view in the sagittal plane. An accurate appreciation of the anatomy of this area is important in avoiding this error. Figure $4 \mathrm{~b}$ shows a coronal MR in which the PMFL passes from lateral to medial across the intercondylar notch. Singson described the appearance of bucket-handle tears of the medial meniscus on MRI and their differentiation from other structures of low-signal intensity in the intercondylar notch. ${ }^{12} \mathrm{He}$ considered that the AMFL could be recognised by its relatively small size and close relationship to the PCL. ${ }^{12}$ We found that in some knees the AMFL is quite large (midpoint width 1.70 to $7.05 \mathrm{~mm}$ (males), 1.50 to $4.45 \mathrm{~mm}$ (females)).

It has been suggested that the presence of the MFL may have a stabilising effect after an isolated PCL tear; it is

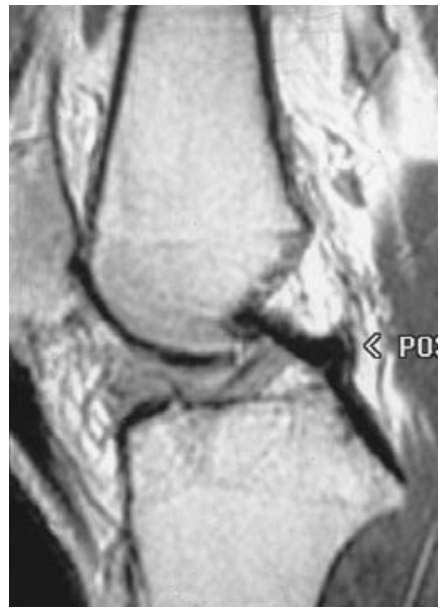

Fig. 4a

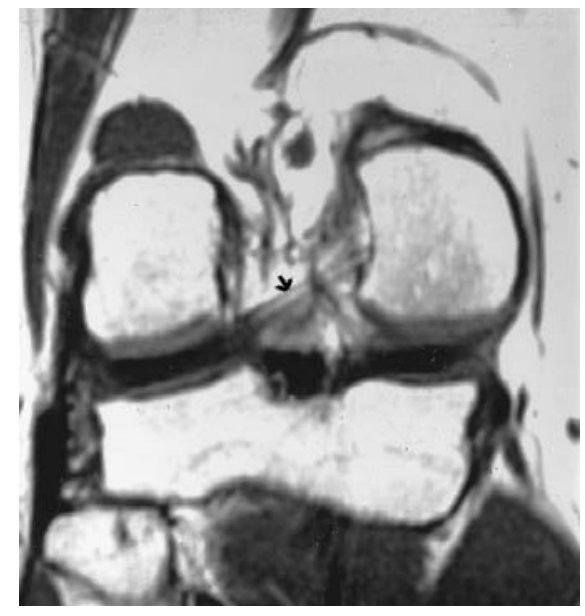

Fig. 4b
Figure 4a - Sagittal T1-weighted MRI showing the posterior meniscofemoral ligament near its origin from the posterior horn of the lateral meniscus. Figure $4 \mathrm{~b}-$ Coronal T1-weighted MRI showing the posterior meniscofemoral ligament passing from lateral to medial across the intercondylar notch. 
reported that the posterior-drawer test in internal rotation may be less obvious because of this. ${ }^{7,8}$ The functional anatomy of the posterior horn of the lateral meniscus is complex and is still poorly understood. We found meniscofemoral ligaments in all our specimens. Although their full functional importance is unknown, their anatomy is important for the interpretation of MR images of the knee.

We wish to acknowledge Dr Frank McGrath, Department of Radiology, Beaumont Hospital, Dublin, for providing us with MR images of the knee and also Mrs Amanda Gageby for her translation of the French literature.

No benefits in any form have been received or will be received from a commercial party related directly or indirectly to the subject of this article.

\section{REFERENCES}

1. Brantigan OC, Voshell AF. The mechanics of the ligaments and menisci of the knee joint. J Bone Joint Surg 1941;23:44-66.

2. Last RJ. Some anatomical details of the knee joint. J Bone Joint Surg [Br] 1948;30-B:683-8.

3. Last RJ. The popliteus muscle and the lateral meniscus: with a note on the attachment of the medial meniscus. J Bone Joint Surg [Br] 1950; 32-B:93-9.

4. Kaplan EB. The lateral menisco-femoral ligament of the knee joint. Bull Hosp Joint Dis 1956;17:176-82.

5. Heller L, Langman J. The menisco-femoral ligaments of the human knee. J Bone Joint Surg [Br] 1964;46-B:307-13.

6. Hughston JC, Bowden JA, Andrews JR, Norwood LA. Acute tears of the posterior cruciate ligament: results of operative treatment. J Bone Joint Surg [Am] 1980;62-A:438-50.

7. Clancy WG, Shelbourne KD, Zoellner GB, et al. Treatment of knee joint instability secondary to rupture of the posterior cruciate ligament: report of a new procedure. J Bone Joint Surg [Am] 1983;65-A: 310-22.
8. Kannus P, Bergfeld J, Jarvinen $\mathbf{M}$, et al. Injuries to the posterior cruciate ligament of the knee. Sports Med 1991;12:110-31.

9. Watanabe AT, Carter BC, Teitelbaum GP, Bradley WG. Common pitfalls in magnetic resonance imaging of the knee. J Bone Joint Surg [Am] 1989;71-A:857-62.

10. Watanabe AT, Carter BC, Teitelbaum GP, Seeger LL, Bradley WG. Normal variations in MR imaging of the knee: appearance and frequency. AJR 1989;153:341-4.

11. Vahey TN, Bennett HT, Arrington LE, Shelbourne KD, Ng J. MR imaging of the knee: pseudotear of the lateral meniscus caused by the meniscofemoral ligament. AJR 1990;154:1237-9.

12. Singson RD, Feldman F, Staron R, Kiernan H. MR imaging of displaced bucket-handle tears of the medial meniscus. AJR 1991; 156:121-4.

13. Robert F. Untersuchungen uber die anatomie und mechanik des kniegelenkes. Ricker, Giessen, 1855.

14. Humphry GM. A treatise on the human skeleton including the joints. Cambridge. Macmillan, 1858:545-6.

15. Poirier P, Charpy A. Traite d'anatomie humaine. Paris: Masson et Cie, 1892-1904.

16. Radoiveitch S. Les ligaments des ménisques interarticulaires du genou. Ann Anat Pathol 1931;8:400-8.

17. Brantigan OC, Voshell AT. Ligaments of the knee joint: the relationship of the ligament of Humphry to the ligament of Wrisberg. $J$ Bone Joint Surg [Am] 1946;28-A:66-7.

18. Lahlaidi A, Vaclavek J. The posterior menisco-femoral ligaments and their significance in organogenesis. Bull Assoc Anat Nancy 1975; 59:177-83.

19. Girgis FG, Marshall JL, al Monajem ARS. The cruciate ligaments of the knee joint: anatomical, functional and experimental analysis. Clin Orthop 1975;106:216-31.

20. Kohn D, Moreno B. Meniscus insertion anatomy as a basis for meniscus replacement: a morphological cadaveric study. Arthroscopy 1995;11:96-103.

21. Lahlaidi A, Vaclavek J. Les ligaments menisci-femeraux posterieurs et leur signification selon l'organogenie. Bull Assoc Anat (Nancy) 1975;59:164:177-83. 